ARTICLE

https://doi.org/10.1038/s41467-019-13178-2

\title{
A sodium-ion sulfide solid electrolyte with unprecedented conductivity at room temperature
}

\author{
A. Hayashi (iD ${ }^{1 \star}$, N. Masuzawa ${ }^{1}$, S. Yubuchi ${ }^{1}$, F. Tsuji ${ }^{1}$, C. Hotehama ${ }^{1}$, A. Sakuda $\mathbb{D}^{1}$ \& M. Tatsumisago ${ }^{1}$
}

Solid electrolytes are key materials to enable solid-state rechargeable batteries, a promising technology that could address the safety and energy density issues. Here, we report a sulfide sodium-ion conductor, $\mathrm{Na}_{2.88} \mathrm{Sb}_{0.88} \mathrm{~W}_{0.12} \mathrm{~S}_{4}$, with conductivity superior to that of the benchmark electrolyte, $\mathrm{Li}_{10} \mathrm{GeP}_{2} \mathrm{~S}_{12}$. Partial substitution of antimony in $\mathrm{Na}_{3} \mathrm{SbS}_{4}$ with tungsten introduces sodium vacancies and tetragonal to cubic phase transition, giving rise to the highest room-temperature conductivity of $32 \mathrm{mS} \mathrm{cm}^{-1}$ for a sintered body, $\mathrm{Na}_{2.88} \mathrm{Sb}_{0.88} \mathrm{~W}_{0.12} \mathrm{~S}_{4}$. Moreover, this sulfide possesses additional advantages including stability against humid atmosphere and densification at much lower sintering temperatures than those $\left(>1000^{\circ} \mathrm{C}\right)$ of typical oxide sodium-ion conductors. The discovery of the fast sodium-ion conductors boosts the ongoing research for solid-state rechargeable battery technology with high safety, costeffectiveness, large energy and power densities.

\footnotetext{
${ }^{1}$ Department of Applied Chemistry, Graduate School of Engineering, Osaka Prefecture University, 1-1 Gakuen-cho, Naka-ku, Sakai, Osaka 599-8531, Japan. *email: hayashi@chem.osakafu-u.ac.jp
} 
$\mathrm{D}$ evelopment of all-solid-state rechargeable batteries has been desired because they have superior characteristics, such as a long cycle life, high safety, high-energy density, and high rate capability ${ }^{1-4}$. To realize bulk-type solid-state batteries using electrodes and electrolyte particles, superior solid electrolytes with high ionic conductivity and good ductility are desired, as they can facilitate wide contact areas with active materials simply upon pressing, without a high-temperature-sintering process 5 . Sulfide solid electrolytes meet this demand. Among solid electrolytes, $\mathrm{Li}_{10} \mathrm{GeP}_{2} \mathrm{~S}_{12}$ (LGPS)-type crystalline sulfides ${ }^{4,6}$ show excellent Li-ion conductivity of over $10^{-2} \mathrm{~S} \mathrm{~cm}^{-1}$, which is higher than that of the conventional organic liquid electrolyte used in lithium-ion batteries, considering its low $\mathrm{Li}^{+}$transference number (below 0.5). Since our discovery of cubic $\mathrm{Na}_{3} \mathrm{PS}_{4}$ with a relatively high $\mathrm{Na}$ ion conductivity of $>10^{-4} \mathrm{~S} \mathrm{~cm}^{-1}$ in $2012^{7}$, studies for developing new Na-ion-conducting sulfides ${ }^{8-22}$ have rapidly increased. In 2016, a good Na-ion conductivity of $1 \times 10^{-3} \mathrm{~S} \mathrm{~cm}^{-1}$ was achieved in $\mathrm{Na}_{2.9375} \mathrm{PS}_{3.9375} \mathrm{Cl}_{0.0625}{ }^{10}$ with $\mathrm{Na}$ vacancies and sodium antimony sulfide, $\mathrm{Na}_{3} \mathrm{SbS}_{4}{ }^{11-13}$. In addition, several other sulfides including $\mathrm{Na}_{11} \mathrm{Sn}_{2} \mathrm{PS}_{12}{ }^{16,17}$ and $\mathrm{Na}_{3} \mathrm{SbSe}_{4}{ }^{18}$ exhibit Na-ion conductivities higher than $10^{-3} \mathrm{~S} \mathrm{~cm}^{-1}$ at $25^{\circ} \mathrm{C}$. However, $\mathrm{Na}_{10} \mathrm{GeP}_{2} \mathrm{~S}_{12}$ (NGPS) ${ }^{22}$ exhibits a moderate $\mathrm{Na}$-ion conductivity of $10^{-5} \mathrm{~S} \mathrm{~cm}^{-1}$, which is much lower than the Li-ion conductivity of LGPS, implying that compositions that impart good Li-ion conductivity do not essentially impart good Na-ion conductivity.

Further, typical oxide crystalline electrolytes of NASICON ${ }^{23}$ and $\beta$-alumina ${ }^{24}$ sintered at high temperatures show a high $\mathrm{Na}$ ion conductivity of $10^{-3} \mathrm{~S} \mathrm{~cm}^{-1}$. As for electrolytes with typical NASICON structure, the Na-ion conductivity in $\mathrm{Na}_{3} \mathrm{Zr}_{2} \mathrm{Si}_{2} \mathrm{PO}_{12}{ }^{23}$ is higher than the Li-ion conductivity in NASICON-type $\mathrm{Li}_{1.3} \mathrm{Al}_{0.3} \mathrm{Ti}_{1.7}\left(\mathrm{PO}_{4}\right)_{3}{ }^{25}$, which implies that the Na-ion mobility in solid electrolytes is inherently higher than the Li ion mobility. This is because of the weaker Lewis acidity of $\mathrm{Na}$ ions, which have weaker electrostatic interaction with the oxide or sulfide anion species constituting the crystalline structure. However, Na-ion conducting sulfide electrolytes with the same degree of conductivity as that of the best Li ion conductor, LGPS, have not been discovered.

Here we report a sulfide Na-ion conductor with ionic conductivity higher than the best Li-ion conductivity of $2.5 \times 10^{-2} \mathrm{~S}$ $\mathrm{cm}^{-1}$ in LGPS-type $\mathrm{Li}_{9.54} \mathrm{Si}_{1.74} \mathrm{P}_{1.44} \mathrm{~S}_{11.7} \mathrm{Cl}_{0.3}{ }^{4}$. The sulfide superionic conductor with the composition of $\mathrm{Na}_{2.88} \mathrm{Sb}_{0.88} \mathrm{~W}_{0.12} \mathrm{~S}_{4}$, obtained by replacing some of the antimony ions in $\mathrm{Na}_{3} \mathrm{SbS}_{4}$ by aliovalent tungsten ions, exhibits a room temperature conductivity of $3.2 \times 10^{-2} \mathrm{~S} \mathrm{~cm}^{-1}$ in a sintered body; the conductivity is superior to those of any reported Li-ion and $\mathrm{Na}$-ion conductors. In addition, the electrolyte shows good stability against hydrolysis, which is the origin of $\mathrm{H}_{2} \mathrm{~S}$ gas evolution in an air atmosphere. The crystalline structure and electrical properties of $\mathrm{Na}_{2.88} \mathrm{Sb}_{0.88} \mathrm{~W}_{0.12} \mathrm{~S}_{4}$ are also demonstrated and discussed.

\section{Results}

Material synthesis and structure analysis. A mechanochemical process using a planetary ball mill apparatus was used to directly produce crystalline $\mathrm{Na}_{3} \mathrm{SbS}_{4}$ (Supplementary Fig. 6a), and its crystallinity increased after heat treatment at $275^{\circ} \mathrm{C}$ for durations ranging from 1.5 to $12 \mathrm{~h}$. X-ray diffraction (XRD) patterns of the $\mathrm{Na}_{3-x} \mathrm{Sb}_{1-x} \mathrm{~W}_{x} \mathrm{~S}_{4}(x=0$ and 0.12$)$ electrolytes prepared by heat treatment are shown in Fig. 1a. The three Raman bands around 360,380 , and $410 \mathrm{~cm}^{-1}$ in the Raman spectrum (Fig. 1b) of the prepared $\mathrm{Na}_{2.88} \mathrm{Sb}_{0.88} \mathrm{~W}_{0.12} \mathrm{~S}_{4}$ reveals the presence of $\mathrm{SbS}_{4}{ }^{3-}$ units, while the Raman band at $\sim 470 \mathrm{~cm}^{-1}$ corresponds to the presence of $\mathrm{WS}_{4}{ }^{2-}$ units, which are typically observed for crystalline $\mathrm{Na}_{2} \mathrm{WS}_{4}$. A fairly weak peak at $\sim 420 \mathrm{~cm}^{-1}$, probably due to $\mathrm{WS}_{2}$, is observed in the spectrum of $\mathrm{Na}_{2.88} \mathrm{Sb}_{0.88} \mathrm{~W}_{0.12} \mathrm{~S}_{4}$ heated for
$1.5 \mathrm{~h}$, while no peak is observed for that heated for $12 \mathrm{~h}$. The Raman bands of the other starting materials $\left(\mathrm{Sb}_{2} \mathrm{~S}_{3}, \mathrm{Na}_{2} \mathrm{~S}, \mathrm{~S}_{8}\right)$ are not observed in the spectra of $\mathrm{Na}_{2.88} \mathrm{Sb}_{0.88} \mathrm{~W}_{0.12} \mathrm{~S}_{4}$ (Supplementary Fig. 1). Cross-section of the pelletized $\mathrm{Na}_{2.88} \mathrm{Sb}_{0.88} \mathrm{~W}_{0.12} \mathrm{~S}_{4}$ heated at $275^{\circ} \mathrm{C}$ for $12 \mathrm{~h}$ was observed by field-emission scanning electron microscopy (FE-SEM), and the secondary electron (SE) and backscattered electron (BSE) images are shown in Fig. 1c. As no composition-dependent contrast is observed in the BSE image, all the elements including tungsten are assumed to be uniformly dispersed in the monitored cross-section. In addition, energy-dispersive X-ray spectroscopic (EDX) mapping indicates the presence of tungsten in the entire SEM area (Supplementary Fig. 2). Elemental analysis using Rutherford backscattering spectrometry (RBS) predicts that the composition is $\mathrm{Na}_{2.88} \mathrm{Sb}_{0.86} \mathrm{~W}_{0.11} \mathrm{~S}_{4}$, and the error in the analysis of antimony is $0.86 \pm 0.04$. The experimentally determined composition is almost the same as the nominal composition of $\mathrm{Na}_{2.88} \mathrm{Sb}_{0.88} \mathrm{~W}_{0.12} \mathrm{~S}_{4}$.

Rietveld refinement analysis was conducted for the powder XRD pattern of the prepared $\mathrm{Na}_{2.88} \mathrm{Sb}_{0.88} \mathrm{~W}_{0.12} \mathrm{~S}_{4}$ (Fig. 2a) and the results are shown in Supplementary Table 1. $\mathrm{Na}_{2.88} \mathrm{Sb}_{0.88} \mathrm{~W}_{0.12} \mathrm{~S}_{4}$ has a cubic structure $(a=7.1920(1) \AA, I-43 m$ (no. 217), and the unit cell consists of a body-centered sublattice with $\mathrm{SbS}_{4}{ }^{3-}$ and $\mathrm{WS}_{4}{ }^{2-}$ units, and tungsten occupies the antimony site $(2 a)$, as shown in Fig. 2b. The W occupancy is $0.078(5)$, which is smaller than the W content at the nominal composition. The EDX and $\mathrm{RBS}$ results show that $\mathrm{Sb}$ is replaced by $\mathrm{W}$ based on the nominal composition. The $\mathrm{W}$ occupancy mismatch is believed to be based on the quality of XRD data measured using a laboratory X-ray diffractometer. Three-dimensional (3D) conduction of $\mathrm{Na}$ ions is expected in this cubic structure. The occupancy of the Na site (6b) is $0.974(2)$, suggesting the creation of vacancies in the lattice. The relatively large atomic displacement factor $(\boldsymbol{B})$ of $\mathrm{Na}$ may be related to the dynamic motion of $\mathrm{Na}$ ions, as observed in the cubic $\mathrm{Na}_{3} \mathrm{PS}_{4}$ phase ${ }^{26}$. Detailed structural analysis using synchrotron XRD is important to determine the W/Sb site occupancy and Na site vacancy in $\mathrm{Na}_{2.88} \mathrm{Sb}_{0.88} \mathrm{~W}_{0.12} \mathrm{~S}_{4}$. In contrast, $\mathrm{Na}_{3} \mathrm{SbS}_{4}(x=$ $0)$ has a tetragonal structure $(a=7.1708(12) \AA, c=7.2376(2) \AA$, $P-42{ }_{1} c$ (no. 114)), which is in good agreement with the previous reports ${ }^{11,12}$; The value of $S$ obtained by the Rietveld refinement of $\mathrm{Na}_{3} \mathrm{SbS}_{4}$ assuming a cubic phase was higher (i.e. $S=R_{\mathrm{wp}} / R_{\mathrm{e}}=$ 3.34) than that $(S=1.98)$ obtained assuming a tetragonal phase. Tetragonal $\mathrm{Na}_{3} \mathrm{SbS}_{4}$ has two $\mathrm{Na}$ sites and their occupancies are unity, as shown in Supplementary Fig. 3 and Supplementary Table 2. Na ion conduction along the $c$-axis in the tetragonal phase would be less likely than in the cubic phase ${ }^{12}$. It is noteworthy that the inclusion of tungsten into crystalline $\mathrm{Na}_{3} \mathrm{SbS}_{4}$ is effective in introducing $\mathrm{Na}$ vacancies in the lattice, and it facilitates the formation of a cubic phase, which can facilitate isotropic 3D fast-ion conduction.

Conduction characteristics. Conductivity of the pelletized $\mathrm{Na}_{2.88} \mathrm{Sb}_{0.88} \mathrm{~W}_{0.12} \mathrm{~S}_{4}$ was measured by the AC impedance method. Pellets of the material were prepared by cold-pressing the electrolyte powder at $1080 \mathrm{MPa}$, followed by heat treatment at $275^{\circ} \mathrm{C}$. Figure 3a shows its conductivity at $25^{\circ} \mathrm{C}\left(\sigma_{25}\right)$ and activation energy $E_{\mathrm{a}}$ for conduction as functions of the duration of heating at $275^{\circ} \mathrm{C}$. As an example, Nyquist plots at $-25^{\circ} \mathrm{C}$ for the pellets heated for 1.5 and $12 \mathrm{~h}$ are shown in Supplementary Fig. 4a, and the cross-sectional SEM image of the pellets are shown in Supplementary Fig. 4b. Only a spike owing to the capacitance at the interface between each electrolyte pellet and Au current collector is observed; other resistance components are not clearly detected in the high-frequency region even at a low measurement temperature of $-25^{\circ} \mathrm{C}$. In this study, the total conductivity is thus determined from the resistance at the intersection of the spike 
a

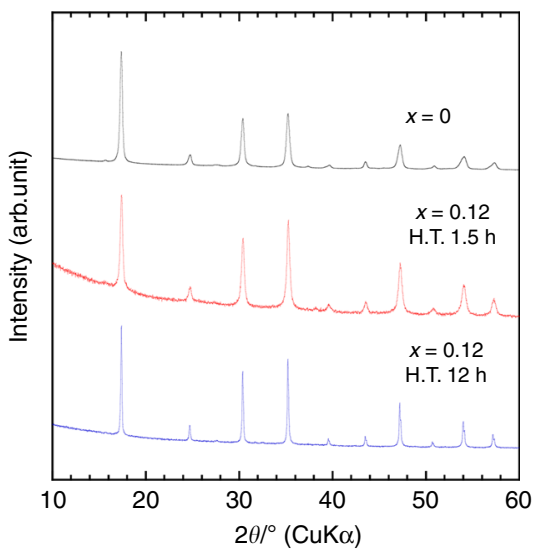

b

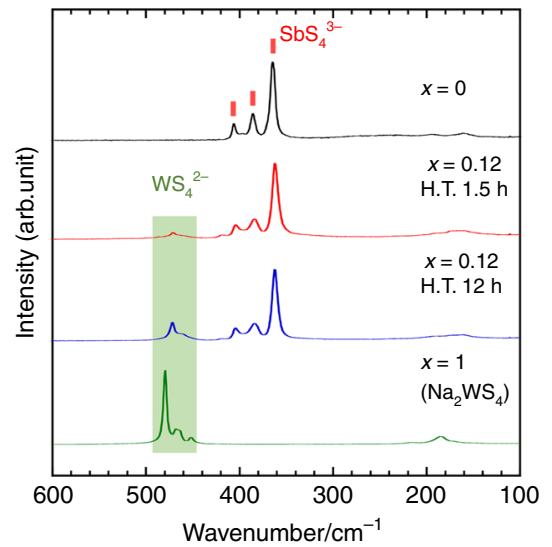

C
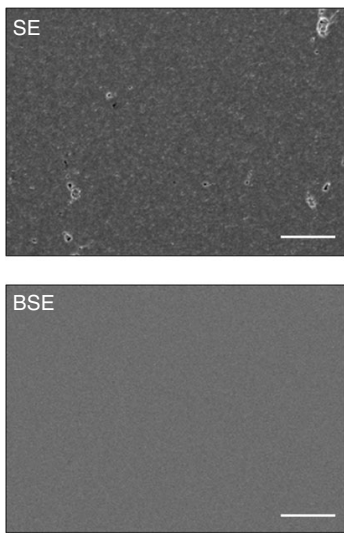

Fig. 1 Structural data for $\mathrm{Na}_{3-x} \mathrm{Sb}_{1-x} \mathrm{~W}_{x} \mathrm{~S}_{4}(x=0$ and 0.12$)$ electrolytes prepared by heat treatment (H.T.) at $275^{\circ} \mathrm{C}$ for $1.5-12 \mathrm{~h}$. a X-ray diffraction patterns, b Raman spectra, and c cross-sectional SEM images (scale bar: $1 \mu \mathrm{m}$ ) of the prepared $\mathrm{Na}_{3-x} \mathrm{Sb}_{1-x} \mathrm{~W}_{x} \mathrm{~S}_{4}$
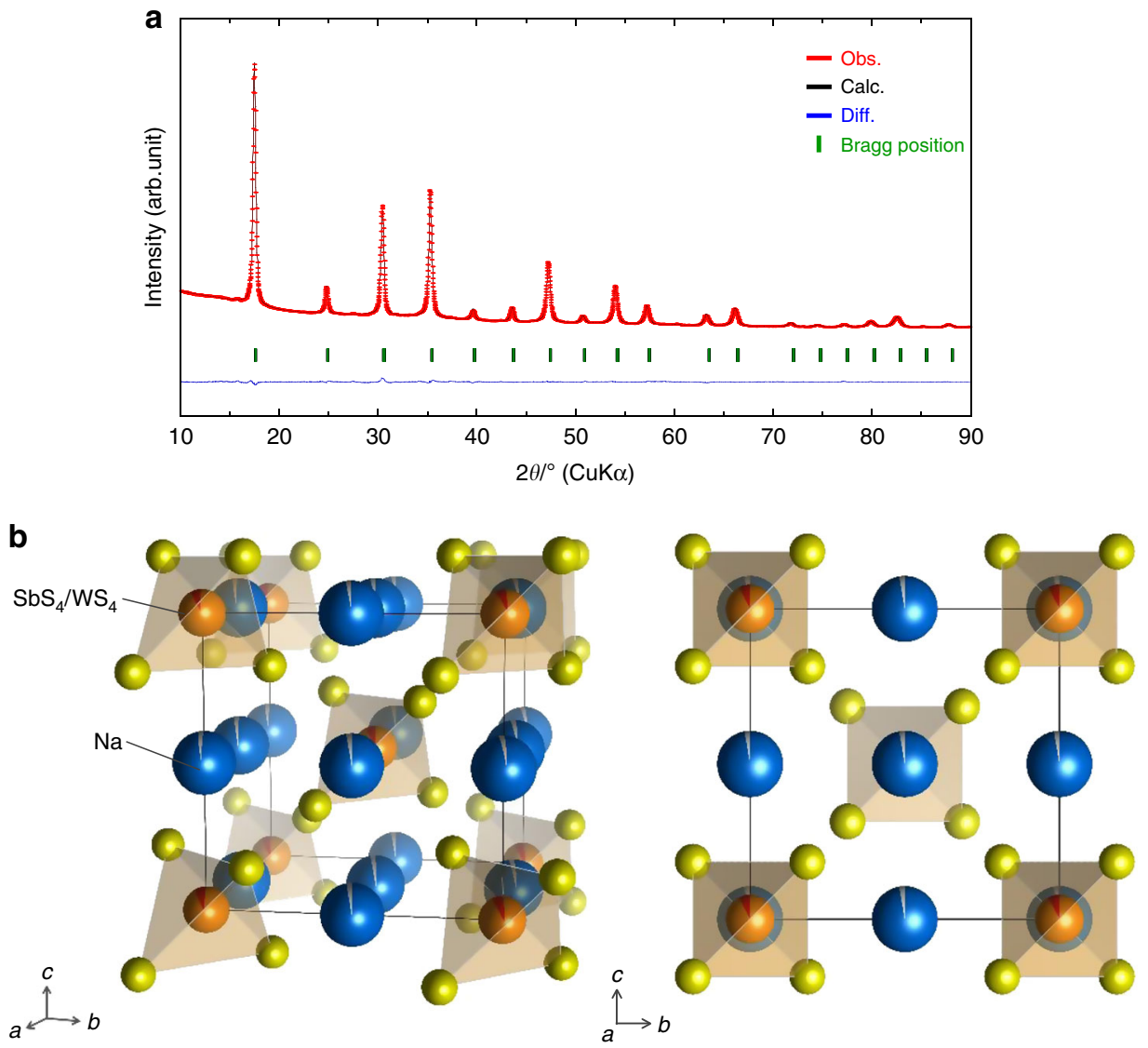

Fig. 2 Crystal structure of $\mathrm{Na}_{2.88} \mathrm{Sb}_{0.88} \mathrm{~W}_{0.12} \mathrm{~S}_{4}$ heated at $275^{\circ} \mathrm{C}$ for $12 \mathrm{~h}$. a Rietveld refinement profiles of X-ray powder diffraction data for $\mathrm{Na}_{2.88} \mathrm{Sb}_{0.88} \mathrm{~W}_{0.12} \mathrm{~S}_{4}$. Red dots and black lines denote the observed and calculated XRD patterns, respectively. The green sticks mark the position of the reflections for $\mathrm{Na}_{2.88} \mathrm{Sb}_{0.88} \mathrm{~W}_{0.12} \mathrm{~S}_{4}$. The difference between the observed and calculated patterns is indicated by the blue line. $\mathbf{b}$ Crystal structure of cubic $\mathrm{Na}_{2.88} \mathrm{Sb}_{0.88} \mathrm{~W}_{0.12} \mathrm{~S}_{4}$ with the unit cell outlined. The $\mathrm{Na}$, Sb, W, and $\mathrm{S}$ sites are represented by blue, orange, gray, and yellow balls, respectively. Na is

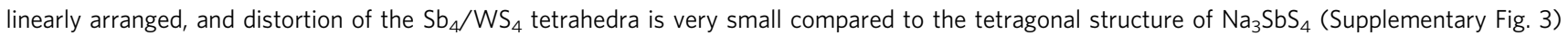

and the $x$-axis; this resistance refers to the total resistance including both the grain-bulk and grain-boundary components of the electrolytes.

The pellet heated for $1.5 \mathrm{~h}$ (relative density of $93 \%$ ) has $\sigma_{25}$ of $1.7 \times 10^{-2} \mathrm{~S} \mathrm{~cm}^{-1}$ and $E_{\mathrm{a}}$ of $19 \mathrm{~kJ} \mathrm{~mol}^{-1}$. The electronic conductivity at $25^{\circ} \mathrm{C}$ measured by a DC polarization technique is $7.9 \times 10^{-8} \mathrm{~S} \mathrm{~cm}^{-1}$ or lower, as shown in Supplementary Fig. 5, which is five orders of magnitude lower than the total conductivity mentioned above; the Na-ion transport number of the prepared $\mathrm{Na}_{2.88} \mathrm{Sb}_{0.88} \mathrm{~W}_{0.12} \mathrm{~S}_{4}$ is almost unity. Na-ion conductivity increased with an increase in the heating time as shown in Fig. 3a, because of the increase in the crystallinity of the cubic phase as well as the relative density of the pellet, as determined by the XRD analysis (Supplementary Fig. 6) and cross-sectional SEM imaging (Supplementary Fig. 4b). The best conducting behavior is obtained for a pellet with a 

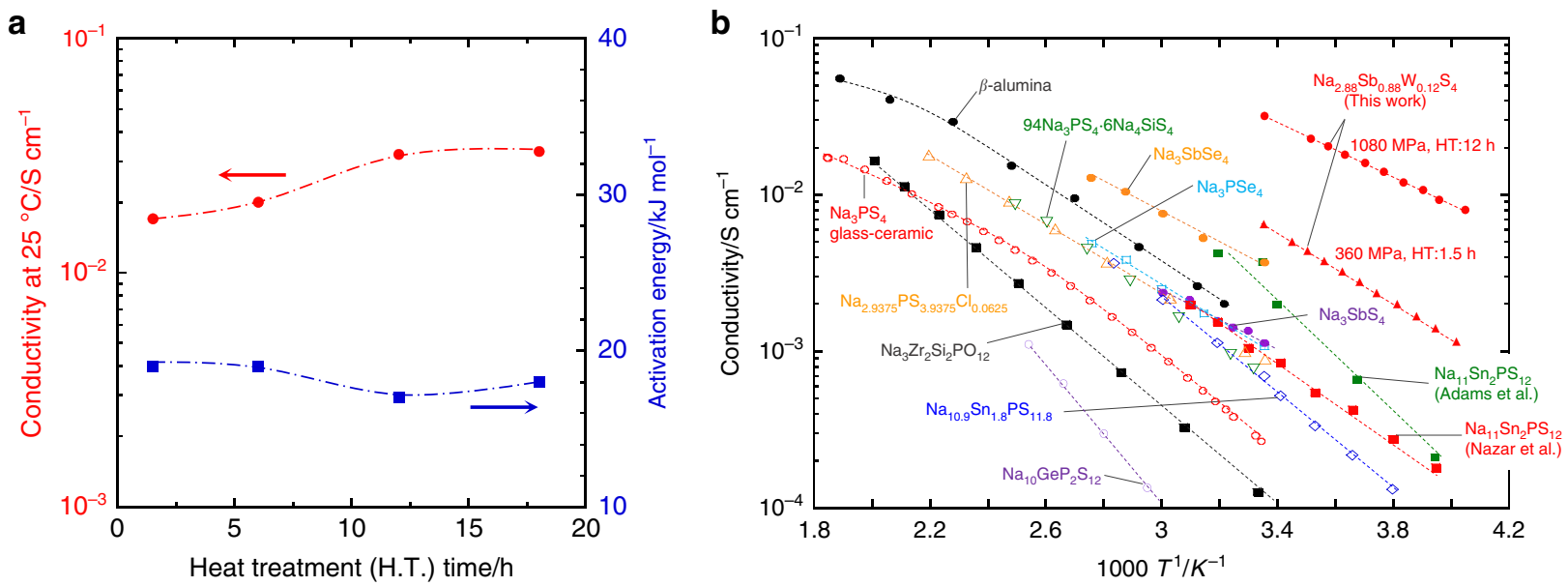

Fig. 3 Conductive behavior of $\mathrm{Na}_{2.88} \mathrm{Sb}_{0.88} \mathrm{~W}_{0.12} \mathrm{~S}_{4}$ electrolyte. a Conductivity at $25^{\circ} \mathrm{C}\left(\sigma_{25}\right)$ and activation energy $E_{\mathrm{a}}$ for the conduction of the pelletized $\mathrm{Na}_{2.88} \mathrm{Sb}_{0.88} \mathrm{~W}_{0.12} \mathrm{~S}_{4}$ electrolytes as a function of heat treatment (H.T.) time at $275^{\circ} \mathrm{C}$. The pellets were prepared by cold-pressing the electrolyte powder at $1080 \mathrm{MPa}$, followed by heat treatment at $275^{\circ} \mathrm{C}$. b The Arrhenius plot of the $\mathrm{Na}$ ion conductivity of the $\mathrm{Na}_{2.88} \mathrm{Sb}_{0.88} \mathrm{~W}_{0.12} \mathrm{~S}_{4}$ electrolyte developed in this study and representative $\mathrm{Na}$ ion conductors reported so far

relative density of $95 \%$ obtained after heating for $12 \mathrm{~h}$, which shows the highest $\sigma_{25}$ of $3.2 \times 10^{-2} \mathrm{~S} \mathrm{~cm}^{-1}$ and the lowest $E_{\mathrm{a}}$ of $17 \mathrm{~kJ} \mathrm{~mol}^{-1}$.

Further, the conductivity of the material is definitely affected by the tungsten content $(x)$ of $\mathrm{Na}_{3-x} \mathrm{Sb}_{1-x} \mathrm{~W}_{x} \mathrm{~S}_{4}$. Pellets of $\mathrm{Na}_{3-x} \mathrm{Sb}_{1-x} \mathrm{~W}_{x} \mathrm{~S}_{4}$ with varying $x$ were prepared by cold-pressing the milled $\mathrm{Na}_{3-x} \mathrm{Sb}_{1-x} \mathrm{~W}_{x} \mathrm{~S}_{4}$ powders at $360 \mathrm{MPa}$, followed by heating at $275^{\circ} \mathrm{C}$ for $1.5 \mathrm{~h}$. XRD patterns of these pellets indicate the formation of cubic crystals without any impurity phases at all the compositions (Supplementary Fig. 7b). No apparent peak shift in the XRD patterns is observed with increasing $x$. This is probably because of the nearly same ionic radii of $\mathrm{Sb}^{5+}$ and $\mathrm{W}^{6+}$. The temperature-dependence of conductivities of the prepared pellets obeys the Arrhenius equation (Supplementary Fig. 6c). The conductivity increases and the activation energy decreases with an increase in $x$, and better conductive behavior is achieved for $x$ ranging from 0.12 to 0.15 (Supplementary Table 3). The electrolyte with $x=0.12$ gives the lowest $E_{\mathrm{a}}$ of $21 \mathrm{~kJ} \mathrm{~mol}^{-1}$ and a high conductivity of $6.4 \times 10^{-3} \mathrm{~S} \mathrm{~cm}^{-1}$, which are superior to those of $\mathrm{Na}_{3} \mathrm{SbS}_{4}(x=0)\left(\sigma_{25}\right.$ of $2.1 \times 10^{-3} \mathrm{~S} \mathrm{~cm}^{-1}$ and $E_{\mathrm{a}}$ of 26 $\left.\mathrm{kJ} \mathrm{mol}^{-1}\right)$. Although this comparison is carried out among the lower density pellets prepared at a smaller molding pressure and a shorter heating time, the partial substitution of tungsten for antimony definitely improves the $\mathrm{Na}$-ion conductivity of the $\mathrm{Na}_{3} \mathrm{SbS}_{4}$ electrolyte.

The Arrhenius plot of the Na-ion conductivity of the $\mathrm{Na}_{2.88} \mathrm{Sb}_{0.88} \mathrm{~W}_{0.12} \mathrm{~S}_{4}$ electrolyte developed in this study is shown in Fig. 3b; it shows the highest conductivity among Na-ion conductors reported so far. In addition, $\sigma_{25}$ of $3.2 \times 10^{-2} \mathrm{~S} \mathrm{~cm}^{-1}$ for the electrolyte is higher than that of the best LGPS-type $\mathrm{Li}_{9.54} \mathrm{Si}_{1.74} \mathrm{P}_{1.44} \mathrm{~S}_{11.7} \mathrm{Cl}_{0.3}$ Li-ion conductor $\left(\sigma_{25}=2.5 \times 10^{-2} \mathrm{~S} \mathrm{~cm}^{-1}\right)$. Here, we have successfully discovered for the first time, a Na-ionconducting sulfide electrolyte that has higher conductivity than all known Li-ion conductors.

Exposure to the atmosphere. Another advantage of the $\mathrm{Na}_{2.88} \mathrm{Sb}_{0.88} \mathrm{~W}_{0.12} \mathrm{~S}_{4}$ electrolyte is its high tolerance to air; that is, the amount of harmful $\mathrm{H}_{2} \mathrm{~S}$ generated when it is exposed to air is almost negligible. $\mathrm{H}_{2} \mathrm{~S}$ generation from the electrolyte even under a highly humid environment (relative humidity, R.H. of 70\%) is suppressed when compared to that from a conventional $\mathrm{Na}_{3} \mathrm{PS}_{4}$ under a less-humid condition with R.H. of $50 \%$ (Fig. 4). An XRD pattern similar to that of the hydrate, $\mathrm{Na}_{3} \mathrm{SbS}_{4} \cdot 9 \mathrm{H}_{2} \mathrm{O}$ is observed

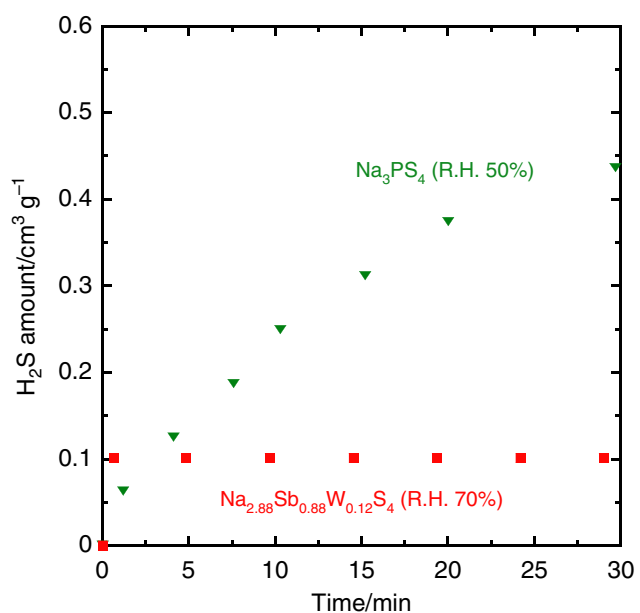

Fig. 4 Monitoring $\mathrm{H}_{2} \mathrm{~S}$ gas generated from $\mathrm{Na}_{2.88} \mathrm{Sb}_{0.88} \mathrm{~W}_{0.12} \mathrm{~S}_{4}$ as a function of exposure time to humid air (relative humidity (R.H.) $=70 \%$ ). The $\mathrm{H}_{2} \mathrm{~S}$ content is normalized by the weight of sulfur in the samples. For comparison, the same measurement was carried out for $\mathrm{Na}_{3} \mathrm{PS}_{4}$ under a less-humid condition of R.H. $=50 \%$

for the electrolyte after exposure to humid air (Supplementary Fig. 8). The formation of a hydrate compound without $\mathrm{H}_{2} \mathrm{~S}$ generation has already been reported for crystalline $\mathrm{Na}_{3} \mathrm{SbS}_{4}{ }^{11}$; our tungsten-substituted sulfide conductor also undergoes a similar structural transformation with hydration.

\section{Discussion}

In conclusion, a $\mathrm{Na}_{2.88} \mathrm{Sb}_{0.88} \mathrm{~W}_{0.12} \mathrm{~S}_{4}$ superionic conductor was developed. The conductivity of this material, $3.2 \times 10^{-2} \mathrm{~S} \mathrm{~cm}^{-1}$ is the highest among sulfide $\mathrm{Li}$ and $\mathrm{Na}$-ion conductors reported so far. The generation of $\mathrm{Na}$ vacancies and stabilization of the cubic phase by the partial substitution of antimony in $\mathrm{Na}_{3} \mathrm{SbS}_{4}$ with tungsten are responsible for its superior conduction. The $\mathrm{Na}_{2.88} \mathrm{Sb}_{0.88} \mathrm{~W}_{0.12} \mathrm{~S}_{4}$ electrolyte with high tolerance to $\mathrm{H}_{2} \mathrm{~S}$ gas generation under an ambient atmosphere would improve safety of all-solid-state batteries and reduce manufacturing cost. The developed sulfide superionic conductor contributes to the realization of solid-state batteries with high-energy density and power density. 


\section{Methods}

Material synthesis. $\mathrm{Na}_{3-x} \mathrm{Sb}_{1-x} \mathrm{~W}_{x} \mathrm{~S}_{4}$ solid electrolytes were prepared via a mechanochemical process using a planetary ball mill apparatus (Pulverisette 7, Fritsch $\mathrm{GmbH}$ ). Reagent-grade $\mathrm{Na}_{2} \mathrm{~S}$ (Nagao Co., $99.1 \%$ ), $\mathrm{Sb}_{2} \mathrm{~S}_{3}$ (Nihonseiko Co., 99.8\%), $\mathrm{WS}_{2}$ (Aldrich Chem. Co., 99\%), and S (Aldrich Chem. Co., 99.98\%) powders were used as the starting materials. The starting materials were weighed at stoichiometric compositions of $\mathrm{Na}_{3-x} \mathrm{Sb}_{1-x} \mathrm{~W}_{x} \mathrm{~S}_{4}$ (e.g., the molar ratio of $\mathrm{Na}_{2} \mathrm{~S}: \mathrm{Sb}_{2} \mathrm{~S}_{3}: \mathrm{S}=50.0: 16.7: 33.3$ for $\mathrm{Na}_{3} \mathrm{SbS}_{4}$ and the molar ratio of $\mathrm{Na}_{2} \mathrm{~S}_{2} \mathrm{Sb}_{2} \mathrm{~S}_{3}: \mathrm{S}:$ $\mathrm{WS}_{2}=48.0: 14.7: 33.3: 4$ for $\mathrm{Na}_{2.88} \mathrm{Sb}_{0.88} \mathrm{~W}_{0.12} \mathrm{~S}_{4}$ ). A mixture of the starting materials $(0.6 \mathrm{~g})$ was ground using a mortar and a pestle for $10 \mathrm{~min}$ and placed in a $45 \mathrm{~mL} \mathrm{ZrO}_{2}$ pot containing $250 \mathrm{ZrO}_{2}$ balls of diameter $4 \mathrm{~mm}$. Then, the starting materials were milled at a rotation speed of $510 \mathrm{rpm}$ for 5 or $30 \mathrm{~h}$. It was further subjected to heat treatment at $275^{\circ} \mathrm{C}$ for several hours $(1.5-18 \mathrm{~h})$ in a porcelain crucible to obtain the final $\mathrm{Na}_{3-x} \mathrm{Sb}_{1-x} \mathrm{~W}_{x} \mathrm{~S}_{4}$ electrolytes. The colors of the prepared electrolytes $\mathrm{Na}_{3} \mathrm{SbS}_{4}$ and $\mathrm{Na}_{2.88} \mathrm{Sb}_{0.88} \mathrm{~W}_{0.12} \mathrm{~S}_{4}$ were brown and dark brown, respectively. All the steps were carried out in dry Ar atmosphere.

Material characterization. The crystallographic phase was identified using an Xray diffractometer (SmartLab, Rigaku) with $\mathrm{Cu}-K \alpha$ radiation. Diffraction data were collected in steps of $0.02^{\circ}$ in the $2 \theta$ range $10-60^{\circ}$ at a scan rate of $10^{\circ} \mathrm{min}^{-1}$. X-ray diffraction (XRD) measurements were performed using an airtight vessel with a beryllium window to prevent the sample from exposure to air. The crystalline structure was refined using the computer program PDXL2 (Rigaku Co.), and the crystal models were visualized using the VESTA software ${ }^{27}$. Rietveld refinement was performed for the XRD data collected in steps of $0.02^{\circ}$ in the $2 \theta$ range $10-120^{\circ}$ at a scan rate of $2^{\circ} \mathrm{min}^{-1}$. For this, first, the peak shape, background coefficient, scale factor, and lattice constants were refined. Then, the occupancy was fixed at the stoichiometric composition, and the atomic displacement factor was refined. Finally, the above parameters were fixed, and the occupancy, except for sulfur, was refined.

Raman spectroscopy was carried out on a Raman spectrophotometer (LabRAM HR-800, Horiba) equipped with a $532 \mathrm{~nm} \mathrm{He}-\mathrm{Ne}$ laser to identify the structural units. The electrolyte samples were placed in an airtight vessel filled with dry $\mathrm{Ar}$ gas, and Raman scattering signals from the samples were collected through a transparent quartz plate mounted on the upper side of the vessel.

Scanning electron microscopy was carried out on a FE-SEM (SU8220, Hitachi High-Technologies) equipped with an energy-dispersive X-ray spectroscopy system (EDX, EMAXEvolution X-MAX, Horiba Ltd.). The samples were transferred from an airtight vessel with dry Ar gas to the apparatus.

The chemical composition was determined by RBS. The RBS measurement was carried out with $\mathrm{He}^{+}$beam accelerated to $2.3 \mathrm{MeV}$ using customized $\mathrm{RC}-43$ (National Electrostatics Co.). The sample was set in a high-vacuum chamber with the sample surface perpendicular to the ion beam. The beam current was measured with a Faraday cup and then tuned to $10 \mathrm{nA}$. Energy spectrum of the backscattered $\mathrm{He}^{+}$was obtained using a surface barrier detector (SBD) set at $160^{\circ}$. The alpha rays emitted from the sample due to nuclear reactions were also detected with an SBD set at $146^{\circ}$. The RBS spectrum was collected for $\sim 2 \mathrm{~h}$ under the measurement condition. The RBS revealed that the ball-milled sample contained about $0.06 \mathrm{wt} \%$ of $\mathrm{Zr}$. The amount is, however, so less that the influence of $\mathrm{Zr}$ contamination from the ball-milling media on the properties of $\mathrm{Na}_{2.88} \mathrm{Sb}_{0.88} \mathrm{~W}_{0.12} \mathrm{~S}_{4}$ is almost negligible.

The amounts of $\mathrm{H}_{2} \mathrm{~S}$ gas evolved from $\mathrm{Na}_{2.88} \mathrm{Sb}_{0.88} \mathrm{~W}_{0.12} \mathrm{~S}_{4}$ were measured using a $\mathrm{H}_{2} \mathrm{~S}$ gas sensor (GBL-HS, JIKCO Co.) and a humidity controller (SCS01, I.E. Service Co.). The $\mathrm{H}_{2} \mathrm{~S}$ gas evolved from $\mathrm{Na}_{3} \mathrm{PS}_{4}$ was also measured for comparison. A powder-compressed pellet $(100 \mathrm{mg})$ was placed in a 2 -L sealed container, where the air humidity and temperature were controlled to $70 \%$ and $24-26^{\circ} \mathrm{C}$, respectively. The amount of $\mathrm{H}_{2} \mathrm{~S}$ was normalized by the mass of sulfur in the samples.

Electrical characterization. The ionic conductivity of pelletized $\mathrm{Na}_{2.88} \mathrm{Sb}_{0.88} \mathrm{~W}_{0.12} \mathrm{~S}_{4}$ electrolytes was measured by the AC impedance method. The data were collected in the range of $10 \mathrm{~Hz}-1 \mathrm{M} \mathrm{Hz}$ using an impedance analyzer (1260, Solartron) with an applied AC voltage of $10-25 \mathrm{mV}$. The milled samples were cold pressed at 360 or $1080 \mathrm{MPa}$ into pellets and then heated at $275^{\circ} \mathrm{C}$ for several hours to obtain the final electrolyte pellets. The diameter and thickness of the pellets were 10 and $\sim 1 \mathrm{~mm}$, respectively. Gold current collectors were used to cover the entire surface of both sides of the pellet. The pellet was sealed in a laminate-type pouch cell to prevent air exposure. The conductivity was measured in the temperature range of ca. -25 to $25^{\circ} \mathrm{C}$, controlled with an ethanol-cooled bath and a constant temperature bath. As an example, three specimens of $\mathrm{Na}_{2.88} \mathrm{Sb}_{0.88} \mathrm{~W}_{0.12} \mathrm{~S}_{4}$ prepared by pressing at $360 \mathrm{MPa}$ and heating at $275^{\circ} \mathrm{C}$ for $1.5 \mathrm{~h}$ showed almost the same conductivities ranging from $6.4 \times 10^{-3}$ to $6.7 \times 10^{-3} \mathrm{~S} \mathrm{~cm}^{-1}$ at $25^{\circ} \mathrm{C}$ (Supplementary Table 3). The activation energy for conduction was calculated from the slope of the Arrhenius equation, $\sigma=\sigma_{0} \exp$ $\left(-E_{\mathrm{a}} / R T\right)$, where $\sigma$ is the ionic conductivity, $T$ is the absolute temperature, $\sigma_{0}$ is the pre-exponential factor for ionic conduction, $E_{\mathrm{a}}$ is the activation energy for the ionic conduction, and $R$ is the gas constant. The errors in activation energy can be considered to be small, because the $R^{2}$ values (coefficient of determination) for the Arrhenius plots exceed 0.99.
The electronic conductivity was measured on electrolyte pellet samples via a DC polarization technique. The data were collected using a potentio/galvanostat (1287, Solartron) with the applied DC voltages ranging from 0.07 to $0.98 \mathrm{~V}$ at $25^{\circ} \mathrm{C}$.

\section{Data availability}

The data that support the findings of this study are available from the corresponding authors upon reasonable request.

Received: 17 January 2019; Accepted: 17 October 2019; Published online: 20 November 2019

\section{References}

1. Takada, K. Progress and prospective of solid-state lithium batteries. Acta Mater. 61, 759-770 (2013).

2. Manthiram, A., Yu, X. \& Wang, S. Lithium battery chemistries enabled by solid-state electrolytes. Nat. Rev. Mater. 2, 16103 (2017).

3. Janek, J. \& Zeier, W. G. A solid future for battery development. Nat. Energy 1, 1-4 (2016).

4. Kato, Y. et al. High-power all-solid-state batteries using sulfide superionic conductors. Nat. Energy 1, 16030 (2016).

5. Hayashi, A., Sakuda, A. \& Tatsumisago, M. Development of sulfide solid electrolytes and interface formation processes for bulk-type all-solid-state $\mathrm{Li}$ and $\mathrm{Na}$ batteries. Front. Energy Res. 4, 1-13 (2016).

6. Kamaya, N. et al. A lithium superionic conductor. Nat. Mater. 10, 682-686 (2011).

7. Hayashi, A., Noi, K., Sakuda, A. \& Tatsumisago, M. Superionic glass-ceramic electrolytes for room-temperature rechargeable sodium batteries. Nat. Commun. 3, 856 (2012).

8. Tanibata, N., Noi, K., Hayashi, A. \& Tatsumisago, M. Preparation and characterization of highly sodium ion conducting $\mathrm{Na}_{3} \mathrm{PS}_{4}-\mathrm{Na}_{4} \mathrm{SiS}_{4}$ solid electrolytes. RSC Adv. 4, 17120-17123 (2014).

9. Zhang, L. et al. $\mathrm{Na}_{3} \mathrm{PSe}_{4}$ : A novel chalcogenide solid electrolyte with high ionic conductivity. Adv. Energy Mater. 5, 1501294 (2015).

10. Chu, I.-H. et al. Room-temperature all-solid-state rechargeable sodium-ion batteries with a Cl-doped $\mathrm{Na}_{3} \mathrm{PS}_{4}$ superionic conductor. Sci. Rep. 6, 33733 (2016).

11. Wang, $\mathrm{H}$. et al. An air-stable $\mathrm{Na}_{3} \mathrm{SbS}_{4}$ superionic conductor prepared by a rapid and economic synthetic procedure. Angew. Chem. Int. Ed. 55, 8551-8555 (2016).

12. Banerjee, A. et al. $\mathrm{Na}_{3} \mathrm{SbS}_{4}$ : a solution processable sodium superionic conductor for all-solid-state sodium-ion batteries. Angew. Chem. Int. Ed. 55, 9634-9638 (2016)

13. Zhang, L. et al. Vacancy-contained tetragonal $\mathrm{Na}_{3} \mathrm{SbS}_{4}$ superionic conductor Adv. Sci. 3, 1600089 (2016).

14. Richards, W. D. et al. Design and synthesis of the superionic conductor $\mathrm{Na}_{10} \mathrm{SnP}_{2} \mathrm{~S}_{12}$. Nat. Commun. 7, 11009 (2016).

15. Krauskopf, T., Pompe, C., Kraft, M. A. \& Zeier, W. G. Influence of lattice dynamics on $\mathrm{Na}^{+}$transport in the solid electrolyte $\mathrm{Na}_{3} \mathrm{PS}_{4-x} \mathrm{Se}_{x}$. Chem. Mater. 29, 8859-8869 (2017).

16. Duchardt, M., Ruschewitz, U., Adams, S., Dehnen, S. \& Roling, B. Vacancycontrolled $\mathrm{Na}^{+}$superion conduction in $\mathrm{Na}_{11} \mathrm{Sn}_{2} \mathrm{PS}_{12}$. Angew. Chem. Int. Ed. 57, 1-6 (2018).

17. Zhang, Z. et al. $\mathrm{Na}_{11} \mathrm{Sn}_{2} \mathrm{PS}_{12}$ : a new solid-state sodium superionic conductor Energy Environ. Sci. 11, 87-93 (2018).

18. Wang, N. et al. Improvement in ion transport in $\mathrm{Na}_{3} \mathrm{PSe}_{4}-\mathrm{Na}_{3} \mathrm{SbSe}_{4}$ by $\mathrm{Sb}$ substitution. J. Mater. Sci. 53, 1987-1994 (2018).

19. $\mathrm{Yu}, \mathrm{Z}$. et al. A quaternary sodium superionic conductor $-\mathrm{Na}_{10.8} \mathrm{Sn}_{1.9} \mathrm{PS}_{11.8}$ Nano Energy 47, 325-330 (2018).

20. Takeuchi, S., Suzuki, K., Hirayama, M. \& Kanno, R. Sodium superionic conduction in tetragonal $\mathrm{Na}_{3} \mathrm{PS}_{4}$. J. Solid State Chem. 265, 353-358 (2018).

21. Moon, C. K. et al. Vacancy-driven $\mathrm{Na}^{+}$superionic conduction in new $\mathrm{Ca}-$ doped $\mathrm{Na}_{3} \mathrm{PS}_{4}$ for all-solid-state Na-ion batteries. ACS Energy Lett. 3, 2504-2512 (2018)

22. Tsuji, F., Tanibata, N., Sakuda, A., Hayashi, A. \& Tatsumisago, M. Preparation of sodium ion conductive $\mathrm{Na}_{10} \mathrm{GeP}_{2} \mathrm{~S}_{12}$ glass-ceramic electrolytes. Chem. Lett. 47, 13-15 (2018).

23. Khireddine, H., Fabry, P., Caneiro, A. \& Bochu, B. Optimization of NASICON composition for $\mathrm{Na}^{+}$recognition. Sens. Actuators B 40, 223-230 (1997).

24. Hooper, A. A study of the electrical properties of single-crystal and polycrystalline $\beta$-alumina using complex plane analysis. J. Phys. D 10, 1487 (1977).

25. Aono, H., Sugimoto, E., Sadaoka, Y., Imanaka, N. \& Adachi, G. Ionic conductivity of the lithium titanium phosphate $\left(\mathrm{Li}_{1+x} \mathrm{M}_{x} \mathrm{Ti}_{2-x}\left(\mathrm{PO}_{4}\right)_{3}, \mathrm{M}=\right.$ $\mathrm{Al}, \mathrm{Sc}, \mathrm{Y}$, and La) systems. J. Electrochem. Soc. 136, 590-591 (1989). 
26. Nishimura, S.-I., Tanibata, N., Hayashi, A., Tatsumisago, M. \& Yamada, A. The crystal structure and sodium disorder of high temperature polymorph $\beta-\mathrm{Na}_{3} \mathrm{PS}_{4}$. J. Mater. Chem. A 5, 25025-25030 (2017).

27. Momma, K. \& Izumi, F. VESTA 3 for three-dimensional visualization of crystal, volumetric and morphology data. J. Appl. Crystallogr. 44, 1272-1276 (2011).

\section{Acknowledgements}

This work was supported by the MEXT program "Elements Strategy Initiative to Form Core Research Center (ESICB)" and JSPS KAKENHI Grant Nos. 18H01713 and 19H05816. RBS measurements were supported by Toray Research Center, Inc.

\section{Author contributions}

A.H. conceived and designed the work and wrote the paper. N.M. performed the material synthesis and characterization. S.Y., F.T., and C.H. conducted XRD analysis, Rietveld refinement, and SEM analysis. A.S., A.H., and M.T. supervised the research. All authors participated in discussions and know the implications of the work.

\section{Competing interests}

The authors declare no competing interests.

\section{Additional information}

Supplementary information is avaliable for this paper at https://doi.org/10.1038/s41467019-13178-2.
Correspondence and requests for materials should be addressed to A.H.

Peer review information Nature Communications thanks Thomas Fassler, Seung-Tae Hong and the other, anonymous, reviewer(s) for their contribution to the peer review of this work.

Reprints and permission information is available at http://www.nature.com/reprints

Publisher's note Springer Nature remains neutral with regard to jurisdictional claims in published maps and institutional affiliations.

cc (i) Open Access This article is licensed under a Creative Commons Attribution 4.0 International License, which permits use, sharing, adaptation, distribution and reproduction in any medium or format, as long as you give appropriate credit to the original author(s) and the source, provide a link to the Creative Commons license, and indicate if changes were made. The images or other third party material in this article are included in the article's Creative Commons license, unless indicated otherwise in a credit line to the material. If material is not included in the article's Creative Commons license and your intended use is not permitted by statutory regulation or exceeds the permitted use, you will need to obtain permission directly from the copyright holder. To view a copy of this license, visit http://creativecommons.org/ licenses/by/4.0/.

(C) The Author(s) 2019 